\title{
BAGAIMANA MELAKUKAN PENILAIAN PROSES PADA PEMBELAJARAN BERBASIS INKUIRI?
}

\author{
Dek Ngurah Laba Laksana \\ STKIP Citra Bakti, NTT \\ laba.laksana@citrabakti.ac.id
}

I Wayan Dasna

Universitas Negeri Malang

idasna2006@yahoo.co.id

\begin{abstract}
Abstrak
Tujuan penulisan ini adalah untuk mengetahui bagaimana cara melakukan penilaian proses pada pembelajaran berbasis inkuiri. Penulisan ini menggunakan kajian literatur melalui telaah jurnal, hasil penelitian yang relevan, dan buku sumber. Hasil analisis menunjukkan bahwa proses penilaian dapat dilakukan pengajar dalam pembelajaran dengan strategi inkuiri adalah penilaian kerja ilmiah. Untuk melakukan penilaian, pengajar menggunakan lembar observasi atau lembar penilaian. Aspek-aspek yang dinilai pada kerja inkuiri mengidentifikasi masalah, mengamati, mengajukan pertanyaan, membuat hipotesis, merencanakan percobaan, melakukan percobaan, menganalisis data, membuat kesimpulan dan generalisasi, dan berkomunikasi.
\end{abstract}

Kata-kata kunci: penilaian, proses, inkuiri

\begin{abstract}
The aimed of this paper is to know how to conduct process assessments on inquiry based instruction. This paper uses literature review through journal review, relevant research results, and book review. The results of the analysis indicate that the assessment process can be done by the teacher in the learning with inquiry strategy is the assessment of scientific work. To conduct an assessment, the teacher uses an observation sheet or assessment sheet. Aspects assessed on inquiry work identify problems, observe, ask questions, hypothesize, plan experiments, experiment, analyze data, make conclusions and generalizations, and communicate.
\end{abstract}

Keywords: assessment, process, inquiry

\section{Pendahuluan}

Strategi inkuiri berupaya menanamkan dasar-dasar berfikir ilmiah pada diri siswa, sehingga dalam proses pembelajaran ini siswa lebih banyak belajar sendiri, mengembangkan kreativitas dalam memecahkan masalah. Siswa benar-benar ditempatkan sebagai subjek yang belajar. Peranan guru dalam pembelajaran dengan metode inkuiri adalah sebagai pembimbing dan fasilitator. Tugas guru adalah memilih masalah yang perlu disampaikan kepada kelas untuk dipecahkan. Namun dimungkinkan juga bahwa masalah yang akan dipecahkan dipilih oleh siswa. Tugas guru selanjutnya adalah menyediakan sumber belajar bagi siswa dalam rangka memecahkan masalah. Bimbingan dan pengawasan guru masih diperlukan, tetapi intervensi terhadap kegiatan siswa dalam pemecahan masalah harus dikurangi.

Pembelajaran inkuiri menekankan kepada proses mencari dan menemukan. Materi pelajaran tidak diberikan secara langsung. Peran siswa dalam pembelajaran ini adalah mencari dan menemukan sendiri materi pelajaran, sedangkan guru berperan sebagai fasilitator dan pembimbing siswa untuk belajar. Pembelajaran inkuiri merupakan rangkaian kegiatan pembelajaran yang menekankan pada proses berpikir kritis dan analitis untuk mencari dan menemukan sendiri jawaban dari suatu masalah yang dipertanyakan. Proses berpikir itu sendiri biasanya dilakukan melalui tanya jawab antara guru dan siswa.

Llewellyn (2013; Laksana, 2017) menjelaskan bahwa mengembangkan sebuah budaya kelas inkuiri dan berargumentasi memberikan kesempatan yang baik bagi guru untuk melibatkan siswa dalam penalaran ilmiah, pengambilan keputusan. Tahapan inkuiri yang penting untuk dilakukan adalah melakukan penilaian. Penilaian merupakan alat untuk memberikan keputusan dan selanjutnya dapat dijadikan dasar evaluasi pembelajaran (Popham, 2006).

Penilaian merupakan kegiatan terstruktur seorang pendidik yang dilakukan secara komprehensif dan terintegrasi dengan proses pembelajaran dengan tujuan untuk menentukan tingkat capaian pembelajaranpeserta didik serta sebagai umpan balik bagi perbaikan proses pembelajaran yang dilaksanakan dengan menggunakan instrumen yang relevan. 


\section{Metode Penelitian}

Penulisan ini menggunakan kajian literatur melalui telaah jurnal, hasil penelitian yang relevan, dan buku sumber. Data yang terkumpul kemudian dianalisis secara deskriptif.

\section{Pembahasan}

Selama proses pembelajaran berlangsung, pengajar melakukan penilaian terhadap kinerja masingmasing subyek didik disamping memberikan fasilitasi belajar mereka. Penilaian yang dilakukan pengajar dalam pembelajaran dengan strategi inkuiri adalah penilaian kerja ilmiah. Untuk melakukan penilaian, pengajar dapat menggunakan lembar observasi atau lembar penilaian untuk setiap aspek penilaian.

Masing-masing aspek yang dinilai dapat menggunakan rentangan skor sesuai dengan kemudahan bagi penilainya. Rentangan skor yang paling mudah digunakan adalah " $y a$ " dan "tidak". Artinya pengajar memberikan penilaian " $y a$ " kalau item yang disyaratkan dilakukan dan "tidak" jika tidak dilakukan. Skor lain yang sering dipakai adalah menggunakan skala Linkert seperti: $1=$ kurang, $2=$ cukup, dan $3=$ baik. Cara lain juga menggunakan rentangan 1 sampai 5 ( $1=$ sangat kurang, $2=$ kurang, $3=$ cukup. $4=$ baik, dan 5 = sangat baik). Skor penilaian yang lebih halus menggunakan rentangan $1-10$. Masing-masing item yang dijelaskan berikut dapat menggunakan skor yang dipilih.

\section{Penilaian pada aspek mengidentifikasi masalah}

Setelah pengajar menyajikan fakta yang akan diselidiki secara inkuiri, subyek didik akan diminta membuat pertanyaan penelitian (research questions) atau rumusan masalah. Pertanyaan-pertanyaan tersebut dinilai oleh pengajar apakah dapat diterima sebagai pertanyaan yang terkait masalah atau belum. Indikator-indikator yang dapat dinilai sebagai berikut.

Tabel 1 Indikator penilaian pertanyaan penyelidikan

\begin{tabular}{clcc}
\hline No. & \multicolumn{1}{c}{ Indikator } & Ya & Tidak \\
\hline 1. & Pertanyaan mengarah pada jawaban Ya dan Tidak & & \\
2. & Berhubungan dengan masalah yang akan dapat diselidiki & \\
3. & Memuat hubungan antar variabel & \\
4. & Dapat diukur/diuji dengan melalui percobaan & \\
5. & Dibuat dalam bentuk kalimat tanya & \\
\hline
\end{tabular}

\section{Penilaian pada aspek mengamati}

Mengamati merupakan kegiatan penting pada kegiatan inkuiri. Dalam proses pengamatan itu subyek didik menggunakan indera. Pada materi yang terkait dengan Sains, pengamatan juga disertai pengukuran. Misalnya mengukur berat suatu benda dengan timbangan, maka subyek didik harus dapat membaca skala timbangan dengan benar. Pada masalah yang ditayangkan dalam video, subyek didik mengamati kejadian demi kejadian secara teliti untuk mengetahui "apa", "mengapa", "oleh siapa" dan sebagainya. Oleh sebab itu, pengajar harus dapat menilai pengamatan yang dilakukan oleh subyek didik. Indikator-indikator penilaian kegiatan pengamatan disajikan pada Tabel 2.

Tabel 2 Indikator penilaian pengamatan

\begin{tabular}{|c|c|c|c|c|}
\hline \multirow[b]{2}{*}{ No } & \multirow[b]{2}{*}{ Indikator } & \multicolumn{3}{|c|}{ Skor } \\
\hline & & $\begin{array}{c}1 \\
\text { (kurang) }\end{array}$ & $\begin{array}{c}2 \\
\text { (cukup) }\end{array}$ & $\begin{array}{c}3 \\
\text { (baik) }\end{array}$ \\
\hline 1. & $\begin{array}{l}\text { Mengamati dengan menggunakan panca indera yang } \\
\text { relevan }\end{array}$ & & & \\
\hline 2. & Membaca hasil pengukuran dengan alat ukur & & & \\
\hline 3. & Mengamati secara cermat dan teliti & & & \\
\hline 4. & Mengutamakan keselamatan kerja ketika mengamati & & & \\
\hline 5. & Mencatat hasil pengamatan dengan jujur & & & \\
\hline
\end{tabular}

\section{Penilaian pada aspek mengajukan pertanyaan}

Mengajukan pertanyaan merupakan tahap yang penting dalam pembelajaran inkuiri. Pertanyaan yang diajukan oleh pengajar adalah untuk mendorong subyek didik bertanya tentang konsep, prinsip, atau hubungan antara variabel yang terkait dengan konsep, prinsip, atau teori. Subyek didik akan mengajukan pertanyaan tentang hubungan antar variabel yang terkait dengan fakta atau masalah yang disajikan oleh pengajar. 
Kualitas pertanyaan subyek didik sangat penting dinilai oleh pengajar. Pertanyaan yang diajukan harus dapat menunjukkan tingkat berpikir subyek didik. Pertanyaan tentang pengetahuan, pemahaman, penerapan, analisis, evaluasi, dan sintesis (mencipta). Makin tinggi tingkatan pertanyaan yang diajukan subyek didik menunjukkan makin tinggi kemampuan berpikirnya dan kemampuan berpikir kritisnya. Ketrampilan berpikir tingkat tinggi atau kemampuan berpikir kritis harus terus dilatih akar subyek didik dapat mengembangkan argumentasi yang rasional berdasarkan fakta dan data yang dimilikinya. Penilaian pertanyaan-pertanyaan yang perlu dinilai oleh pengajar disajikan pada Tabel 3.

Tabel 3 Indikator penilaian pertanyaan dalam strategi inkuiri

\begin{tabular}{|c|c|c|c|c|}
\hline \multirow[b]{2}{*}{ No } & \multirow[b]{2}{*}{ Indikator } & \multicolumn{3}{|c|}{ Skor } \\
\hline & & $\begin{array}{c}1 \\
\text { (kurang) }\end{array}$ & $\begin{array}{c}2 \\
\text { (cukup) }\end{array}$ & $\begin{array}{c}3 \\
\text { (baik) }\end{array}$ \\
\hline 1. & $\begin{array}{l}\text { Pertanyaan terkait dengan masalah yang diamati atau } \\
\text { kejadian yang disajikan }\end{array}$ & & & \\
\hline 2. & $\begin{array}{l}\text { Pertanyaan mengarah pada jawaban divergen atau } \\
\text { jawabannya memerlukan penyelidikan }\end{array}$ & & & \\
\hline 3. & Pertanyaan mengandung hubungan antar variabel & & & \\
\hline 4. & Pertanyaan rasional, logis, atau nalar & & & \\
\hline 5. & $\begin{array}{l}\text { Pertanyaan berdasarkan pengetahuan awal dan teori } \\
\text { yang telah dipelajari }\end{array}$ & & & \\
\hline
\end{tabular}

Indikator-indikator penilaian tersebut datap ditambahkan oleh pengajar bergantung pada konteks masalah yang disajikan. Untuk dapat mengajukan pertanyaan perlu dilatih oleh pengajar. Bila subyek didik mengalami kesulitan dapat memberikan contoh, atau memberikan kata-kata kunci yang harus ada dalam pertanyaan.

\section{Penilaian pada aspek membuat hipotesis}

Sebagaimana telah dijelaskan sebelumnya, hipotesis merupakan jawaban sementara atas pertanyaan penyelidikan yang telah ditetapkan. Jawaban sementara itu dibuat tidak semata-mata berdasarkan dukaan tetapi berdasarkan hasil kajian. Subyek didik dapat menggunakan sumber-sember belajar yang dimiliki atau menelusuri dari internet. Penilaian hipotesis disajikan pada Tabel 4.

Tabel 4 Indikator penilaian hipotesis

\begin{tabular}{|c|c|c|c|c|}
\hline \multirow[b]{2}{*}{ No } & \multirow[b]{2}{*}{ Indikator } & \multicolumn{3}{|c|}{ Skor } \\
\hline & & $\begin{array}{c}1 \\
\text { (kurang) }\end{array}$ & $\begin{array}{c}2 \\
\text { (cukup) }\end{array}$ & $\begin{array}{c}3 \\
\text { (baik) }\end{array}$ \\
\hline 1. & Hipotesis didasarkan atas kajian teori & & & \\
\hline 2. & Hipotesis dapat diukur atau diuji dengan data & & & \\
\hline 3. & $\begin{array}{l}\text { Mengandung jawaban yang tidak menyimpulkan (ada } \\
\text { alternatif jawaban) }\end{array}$ & & & \\
\hline 4. & Jawaban hipotesis diperoleh dari induktif & & & \\
\hline
\end{tabular}

\section{Penilaian pada aspek merencanakan percobaan}

Setelah subyek didik bersama pengajar menetapkan pertanyaan penyelidikan atau sering pula disebut rumusan masalah, kegiatan berikutnya adalah merancang percobaan untuk menjawab pertanyaan penyelidikan dan hipotesis yang ditetapkan. Perencanaan percobaan harus mengacu pada variabel-variabel yang berubah dan yang dikontrol. Misalnya untuk mengetahui kecepatan tumbuh suatu tumbuhan yang ditanam pada medium (tanah) yang berbeda maka umur tumbuhan harus sama. Umur tumbuhan tersebut disebut variabel kontrol sedangkan mediumnya merupakan variabel bebas yang akan dimanipulasi. Oleh sebab itu, penilaian yang dilakukan oleh pengajar harus mengacu pada apakah percobaan yang dirancang dapat mengumpulkan data terhadap variabel yang diubah dan variabel yang disebabkan. Indikator-indikator yang dapat digunakan disajikan pada Tabel 5. 
Tabel 5 Indikator penilaian pada kegiatan merancang percobaan

\begin{tabular}{|c|c|c|c|c|}
\hline \multirow[b]{2}{*}{ No } & \multirow[b]{2}{*}{ Indikator } & \multicolumn{3}{|c|}{ Skor } \\
\hline & & $\begin{array}{c}1 \\
\text { (kurang) }\end{array}$ & $\begin{array}{c}2 \\
\text { (cukup) }\end{array}$ & $\begin{array}{c}\mathbf{3} \\
\text { (baik) }\end{array}$ \\
\hline 1. & Mencakup variabel-variabel yang dimanipulasi & & & \\
\hline 2. & Mencakup variabel-variabel yang dikontrol & & & \\
\hline 3. & Alat-alat yang digunakan aman tetapi relevan & & & \\
\hline 4. & Bahan-bahan yang digunakan tidak membahayakan & & & \\
\hline 5. & Data yang diperoleh terukur dan dibandingkan & & & \\
\hline 6. & Langkah-langkah kerja urut dan dapat dikerjakan & & & \\
\hline 7. & Prosedur ditulis sistematis & & & \\
\hline
\end{tabular}

\section{Penilaian pada aspek melakukan percobaan}

Percobaan merupakan kegiatan penting yang melibatkan subyek didik secara langsung untuk melakukan aktivitas. Pada saat melakukan percobaan, subyek didik belajar ketrampilan proses seperti mengukur, mengamati, mengontrol variabel, teliti, cermat, menggunakan alat dengan benar, dan menggunakan bahan secara efesien. Ketrampilan-ketrampilan ini sangat penting untuk menyiapkan subyek didik sebagai calon ilmuan atau tenaga kerja yang profesional di masa depan.

Tabel 6 Indikator-indiaktor percobaan dalam pembelajaran inkuiri

\begin{tabular}{|c|c|c|c|c|}
\hline \multirow[b]{2}{*}{ No } & \multirow[b]{2}{*}{ Indikator } & \multicolumn{3}{|c|}{ Skor } \\
\hline & & $\begin{array}{c}1 \\
\text { (kurang) }\end{array}$ & $\begin{array}{c}2 \\
\text { (cukup) }\end{array}$ & $\begin{array}{c}3 \\
\text { (baik) }\end{array}$ \\
\hline 1. & Pemilihan alat-alat yang diperlukan dengan benar & & & \\
\hline 2. & Penggunaan bahan sesuai dengan prosedur & & & \\
\hline 3. & Alat-alat digunakan atau dioperasikan dengan benar & & & \\
\hline 4. & $\begin{array}{l}\text { Memanipulasi variabel-variabel percobaan (faktor } \\
\text { yang berubah dan faktor yang dikontrol) dengan benar }\end{array}$ & & & \\
\hline 5. & $\begin{array}{l}\text { Melakukan percobaan sesuai dengan prosedur kerja } \\
\text { yang ditetapkan }\end{array}$ & & & \\
\hline 6. & Menggunakan waktu secara efesien & & & \\
\hline 7. & Kebersihan alat-alat sebelum digunakan & & & \\
\hline 8. & Kebersihan alat-alat setelah digunakan & & & \\
\hline 9. & Keselamatan kerja dalam melakukan percobaan & & & \\
\hline 10. & Kejujuran mencatat hasil pengamatan & & & \\
\hline
\end{tabular}

Penilain yang harus dilakukan pengajar ketika subyek didik melakukan percobaan terkait dengan ketrampilan-ketrampilan (psikomotor) yang dengan apa yang dikerjakannya dan bagaimana mengerjakannya. Percobaan yang dilakukan akan terkait dengan penggunaan alat dan bahan sehingga penilaian juga terkait dengan hal itu. Beberapa indikator yang dapat digunakan acuan dalam penilaian percobaan disajikan pada Tabel 6.

\section{Penilaian pada aspek menganalisis data}

Analisis data merupakan kegiatan penting dalam kegiatan inkuiri. Setelah percobaan dilakukan maka data yang telah dikumpulkan harus diolah oleh subyek didik. Pengolahan data melibuti: pembuatan tabel, pembuatan grafik, menghitung rerata, menentukan kecenderungan, dan menguji adanya hubungan atau perbedaan. Oleh sebab itu, kegiatan analisis data harus dimonitor dengan cermat oleh pengajar agar data yang dianalisis mengarah pada pengujian hipotesis yang dibuat. Hasil analisis data akan menentukan apakah hipotesis yang ditetapkan benar atau salah. Indikator-indikator penilaian analisis data disajikan pada Tabel 7. 
Tabel 7 Indikator analisis data pada kegiatan belajar inkuiri

\begin{tabular}{|c|c|c|c|c|}
\hline \multirow[b]{2}{*}{ No. } & \multirow[b]{2}{*}{ Indikator } & \multicolumn{3}{|c|}{ Skor } \\
\hline & & $\begin{array}{c}1 \\
\text { (kurang) }\end{array}$ & $\begin{array}{c}2 \\
\text { (cukup) }\end{array}$ & $\begin{array}{c}3 \\
\text { (baik) }\end{array}$ \\
\hline 1. & Data dikelompokkan dalam tabel (bila relevan) & & & \\
\hline 2. & Data dibuat dalam bentuk grafik & & & \\
\hline 3. & Data dianalisis untuk menunjukkan kecenderungan & & & \\
\hline 4. & Data dianalisis menunjukkan perbedaan & & & \\
\hline 5. & Data yang dianalisis menunjukkan hubungan & & & \\
\hline 6. & Analisis data menguji hipotesis yang dibuat & & & \\
\hline
\end{tabular}

\section{Penilaian pada aspek membuat kesimpulan dan generalisasi}

Data yang dikumpulkan dan dianalisis digunakan untuk menjawab pertanyaan penelitian atau membuaktikan hipotesis yang dibuat. Setelah hipotesis tersebut terbukti atau tidak terbukti maka subyek didik akan membuat kesimpulan dan generalisasi. Kesimpulan yang dibuat harus dapat menunjukkankonsep atau hubungan antar konsep yang tercakup dalam materi yang dipelajari. Indikator penilaian yang dapat digunakan untuk menilai kesimpulan yang dibuat oleh subyek didik disajikan pada Tabel 8.

Tabel 8 Indikator penilaian kesimpulan dalam kegiatan inkuiri

\begin{tabular}{llcc}
\hline No & \multicolumn{1}{c}{ Indikator } & \multicolumn{3}{c}{ Skor } \\
\cline { 3 - 4 } & & $\mathbf{1}$ & $\mathbf{2}$ \\
1. & $\begin{array}{l}\text { Menunjukkan hubungan antar konsep yang tercakup } \\
\text { dalam masalah yang dibahas }\end{array}$ & & $\mathbf{3}$ \\
(cukup) & (baik) \\
\hline 2. & $\begin{array}{l}\text { Kesimpulan yang logis dan menunjukkan penalaran } \\
\text { ilmiah }\end{array}$ & \\
\hline 3. & Relevan dengan data yang dikumpulakan \\
\hline 4. & $\begin{array}{l}\text { Dituliskan dalam rumusan kesimpulan yang mudah } \\
\text { dipahami }\end{array}$ \\
\hline
\end{tabular}

\section{Penilaian pada aspek berkomunikasi}

Hasil penyelidikan yang dilakukan oleh subyek didik harus dikomunikasikan dan dilaporkan kepada teman-teman sekelasnya. Oleh sebab itu, komunikasi dalam hal ini mencakup laporan kegiatan yang dibuat dalam bentuk poster atau makalah. Laporan dapat dikomunikasikan dalam bentuk presentasi oral menggunakan media seperti power point. Laporan dalam bentuk poster akan dipajang atau ditempelkan di kelas sehingga semua siswa dapat mengamati dan memberikan komentarnya.

Untuk menilai laporan dalam bentuk makalah atau poster, pengajar harus menggunakan lembar penilaian yang disertai dengan rubrik penialian. Pengajar dapat mengembangkan lembar penilaian dari contoh-contoh indikator yang disajikan pada Tabel 9.

Tabel 9 Indikator penilaian komunikasi hasil penyelidikan

\begin{tabular}{|c|c|c|c|c|}
\hline \multirow[b]{2}{*}{ No } & \multirow[b]{2}{*}{ Indikator } & \multicolumn{3}{|c|}{ Skor } \\
\hline & & $\begin{array}{c}1 \\
\text { (kurang) }\end{array}$ & $\begin{array}{c}2 \\
\text { (cukup) }\end{array}$ & $\begin{array}{c}3 \\
\text { (baik) }\end{array}$ \\
\hline 1. & $\begin{array}{l}\text { Laporan hasil dibuat dengan struktur laporan yang } \\
\text { ditetapkan }\end{array}$ & & & \\
\hline 2. & Laporan ditulis dengan tata tulis ilmiah & & & \\
\hline 3. & Kebenaran isi & & & \\
\hline 4. & Laporan dipresentasikan secara singkat dan jelas & & & \\
\hline 5. & Presentasi menarik & & & \\
\hline 6. & Presentasi disampaiakn dengan lancar & & & \\
\hline 7. & $\begin{array}{l}\text { Penguasaan materi (kemampuan menjawab } \\
\text { pertanyaan) }\end{array}$ & & & \\
\hline 8. & Ketepatan atau pengelolaan waktu & & & \\
\hline
\end{tabular}


Penilaian dalam kegiatan belajar dengan inkuiri sangat penting dilakukan pengajar agar subyek didik bekerja dengan sungguh-sungguh dan tujuan pembelajaran dapat tercapai. Pembelajaran dengan inkuiri harus direncanakan dengan baik agar pelaksanaan pembelajaran sesuai dengan tujuan pembelajaran. Demikian juga penilaian pembelajaran harus disampaikan kepada subyek didik sebelum pembelajaran inkuiri dimulai agar mereka mengetahui indikator-indikator yang akan dinilai ketika mereka melakukan aktivitas.

\section{Simpulan}

Proses penilaian dapat dilakukan pengajar dalam pembelajaran dengan strategi inkuiri adalah penilaian kerja ilmiah. Untuk melakukan penilaian, pengajar menggunakan lembar observasi atau lembar penilaian. Aspek-aspek yang dinilai pada kerja inkuiri mengidentifikasi masalah, mengamati, mengajukan pertanyaan, membuat hipotesis, merencanakan percobaan, melakukan percobaan, menganalisis data, membuat kesimpulan dan generalisasi, dan berkomunikasi.

\section{Daftar Pustaka}

Arends, R.I. 2004. Learning to Teach. Sixth Edition. Boston: McGraw Hill.

Dasna, I W., Laksana, D.N.L., \& Sudhata, I G.W. (2015). Desain dan Model Pembelajaran Inovatif dan Interaktif. Jakarta: Universitas Terbuka Press.

Laksana, D.N L. (2017). The Effectiveness of Inquiry Based Learning for Natural Science Learning in Elementary School. Journal of Education Technology, 1(1), 1-5.

Lang, H.R. and Evans, D. N. 2006. Models, Strategies, and Methods for Effective Teaching. Boston: Pearson.

Llewellyn, D. 2013. Teaching Hingh School Science Through Inquiry and Argumentation. $2^{\text {nd }}$ Edition. Thousand Oaks, California: Corwin a SAGE Company.

Ray, B. 2007. Modern Methods of Teaching Chemistry. New Delhi: APH Publishing Cooperation.

Popham, W.J. 2006. Assessment for Education. USA: Pearson Education, Inc 